\title{
Catalytic Ethanolysis of Fructan-rich and Starchy Expired Food into Biofuel 5-Ethoxymethylfurfural
}

\author{
Luxin Zhang, ${ }^{\mathrm{a}, *}$ Yuting Liu, ${ }^{\mathrm{a}}$ Chang Liu, ${ }^{\mathrm{b}}$ Simin $\mathrm{Yi},{ }^{\mathrm{a}}$ Wen Sun, ${ }^{\mathrm{a}}$ and Jianfeng $\mathrm{He}^{\mathrm{a}}$ \\ Catalytic systems were investigated for the ethanolysis of expired food into \\ 5-ethoxymethylfurfural (5-EMF). Fructan-rich expired food (expired \\ probiotics beverage powder, onion powder, garlic powder, and burdock \\ tea), and starchy expired food (expired steamed buns and egg yolk \\ battercake) were tested as starting substrates. Optimization of the reaction \\ conditions included varying the catalyst type, temperature, catalyst \\ loading, and reaction time to maximize 5-EMF yield. Several co-solvents \\ were added to evaluate their impact on the generation of 5 -EMF. The \\ selected expired foods produced 5 -EMF yields ranging from $0.2 \mathrm{~mol} \%$ to \\ $68 \mathrm{~mol} \%$. The 5-EMF yield from fructan-rich expired food was more \\ noticeably affected by the content of the non-carbohydrate part than that \\ from starchy expired food. The effect of co-solvents on conversion \\ efficiency was closely related to the catalyst type but was not strongly \\ correlated with the feedstock used. This study provides a facile way to \\ produce biofuel chemicals from carbohydrate-rich expired food.
}

Keywords: Biorefinery; Biofuel; 5-EMF; Catalysis; Fructan-rich expired food; Starchy expired food

Contact information: a: College of Environmental and Municipal Engineering, Key Laboratory of Northwest Water Resources, Environment, and Ecology, MOE, Key Laboratory of Environmental Engineering, Shaanxi Province, Xi'an University of Architecture and Technology, Xi'an, 710055, P.R. China; $b$ : Department of Civil and Environmental Engineering, College of Engineering and Mellon College of Science, Carnegie Mellon University, 5000 Forbes Ave, Pittsburgh, PA 15213, USA;

*Corresponding author: zhangluxinxx@126.com

\section{INTRODUCTION}

Approximately one third of the food produced globally for human consumption is lost or wasted in food supply chains (FAO 2011; Abeliotis et al. 2015); therefore the valorization of food waste biomass, both pre-consumer and post-consumer food waste, has been of increased interest recently (Pfaltzgraff et al. 2013; Chen et al. 2017; Zhai et al. 2018). Conventional food supply chain waste (FSCW) recycling strategies (first generation food waste treatment and recycling) include anaerobic digestion for biogas generation, composting, bioethanol generation, and animal feed production (Pham et al. 2015). These microbiological treatments have several disadvantages, which include long production times and the underutilization or loss of chemical functionalities. The need to avoid the production of waste and find new renewable resources has led to second generation FSCW valorization approaches, which use FSCW as an alternative to "virgin biomass" to produce bio-derived marketable chemicals, materials, and fuels (Pfaltzgraff et al. 2013; Karmee and Lin 2014; Xiong et al. 2019; Mak et al. 2020). Among these value-added chemicals that are produced using a biorefinery process, furan-derived compounds, such as 5hydroxymethylfurfural (5-HMF), have recently received increased attention (Galaverna et al. 2018; Tyagi et al. 2018). 5-Hydroxymethylfurfural is an important platform molecule that provides an efficient route from waste or biomass derived-carbohydrates to chemicals 
and fuel precursors. Furthermore, 5-HMF derivatives have been utilized for various applications, several of which are in major growth industries (Yu and Tsang 2017). The production of 5-HMF from post-consumer carbohydrate-rich food waste, such as cellulosic food, starchy food, sugary food, and beverage waste, has been investigated (Yu et al. 2016, 2017, and 2018). Appreciable yields of 5-HMF can be obtained from these post-consumer food wastes by the sequential reaction steps of hydrolysis-isomerization-dehydration of carbohydrates in food waste (Parshetti et al. 2015).

Despite the versatile application potential of 5-HMF as an intermediate in the synthesis of liquid transportation fuels, fine chemicals, polymers, solvents, or pharmaceuticals, it has not yet been produced on an industrial scale, which is largely due to high production costs. Although satisfactory 5-HMF yields can be obtained from polar organic solvents (i.e., dimethyl sulfoxide (DMSO) and N,N-dimethylformamide (DMF)), it is prohibitively difficult to separate the target compound from these polar aprotic solvents because their boiling points are relatively high (this is energy intensive and costineffective), and substantial product loss occurs due to the inherent reactivity of 5-HMF at high temperatures. Furthermore, the hydroxyl group of 5-HMF has a strong affinity for polar organic solvents; thus, isolating 5 -HMF by extraction is challenging.

In alcoholic solvents, the conversion of carbohydrates to 5-HMF occurs under acidic conditions in parallel with 5-HMF etherification reaction with alcohol to produce alkoxymethyl furfurals. 5-HMF is a crucial intermediate product in the conversion of carbohydrates to alkoxymethyl furfurals (Zhu et al. 2017; Guo et al. 2018). Therefore, for the multistep reaction of hydrolysis-isomerization-dehydration to produce 5-HMF from food waste-derived carbohydrates, alcohol is a suitable reaction solvent to permit the etherification reaction (Sun et al. 2018). The selective etherification of the hydroxylmethyl group in 5-HMF to an alkoxymethyl substituent can enable the facile isolation because ethers are more stable. "Extraction + distillation" was found to be feasible for the separation of EMF from the polar organic solvents/ethanol solvent system (Yu et al. 2018; Wang et al. 2013). Alkoxymethyl furfurals have not been explored until recently as fuel chemicals, despite much earlier reports of their synthesis.

Among the alkoxymethyl furfurals, 5-ethoxymethylfurfural (5-EMF) has received notable attention due to its superior physical and chemical properties as a promising liquid biofuel (liquid at room temperature, high volumetric energy density, high cetane number, and good oxidation stability) (Zhang et al. 2018). In addition, 5-EMF has been widely used for flavor adjustment in beers and wines. For 5-EMF production, broad ranges of feedstock from commercial carbohydrates to raw lignocellulosic biomass have been used, and their performances have been evaluated (Alipour et al. 2017). However, the current approaches for producing 5-EMF in appreciable yields are primarily dependent on the conversion of simple monosaccharides, such as fructose and glucose (Chen et al. 2018; Gawade and Yadav 2018; Xu et al. 2020), and the continued use of these edible saccharides may have a negative impact on global food supplies. Although lignocellulosic biomass is a more economically attractive feedstock than commercial carbohydrates, the conversion of lignocellulosic materials to 5-EMF requires harsh reaction conditions and results in low yields of 5-EMF due to their complex, highly polymerized molecular structures.

Therefore, this study considered FSCW that contained large amounts of carbohydrates as an alternative feedstock for 5-EMF production. Past biorefinery of food waste biomass to produce products with high economic value has largely focused on food waste streams produced from the manufacturing stage or post-consumer stage (Arancon $e t$ al. 2013; di Bitonto et al. 2018). However, pre-consumer expired food is also an important 
component of food waste and is generated in a more concentrated and homogeneous manner, but it has not been well explored. Currently, there are three main modes of recycling and processing pre-consumer expired food in China, which include using specialized incinerators to destroy the pre-consumer expired food, directly disposing the pre-consumer expired food with municipal solid waste, and selling the pre-consumer expired food to fertilizer and feed manufacturers at low prices. All these options for disposing pre-consumer expired food do not achieve the goal of maximizing the valueadded reclamation.

This study evaluated the viability of expired starchy and fructan-rich food as substrates for the catalytic production of 5-EMF via ethanolysis reaction. The expired food included probiotic beverage powder, garlic powder, onion powder, burdock tea, steamed buns, and egg yolk battercake that had exceeded their shelf life. For comparison, the activity of these catalytic systems was further studied with the addition of a co-solvent. Further, this study assessed the production of 5-HMF and ethyl levulinate (EL) formation, as they are the main by-products in these reactions and represent important platform chemicals and fuel additives (Démolis et al. 2014; Ahmad et al. 2016; Unlu et al. 2016; Huang et al. 2018). A new catalytic valorization approach for carbohydrate-rich expired food was established, and the conclusions from this study can provide a new approach to pre-consumer food waste reclamation.

\section{EXPERIMENTAL}

\section{Materials and Methods}

Dimethylsulfoxide (99\%) was purchased from Shanghai Macklin Biochemical Co., Ltd. (Shanghai, China). The $\mathrm{H}_{3} \mathrm{PW}_{12} \mathrm{O}_{40}, \mathrm{H}_{3} \mathrm{PMo}_{12} \mathrm{O}_{40}, \mathrm{H}_{4} \mathrm{SiW}_{12} \mathrm{O}_{40}$, and Amberlyst-15 used were purchased from Acros (Geel, Belgium). The H- $\beta, \mathrm{H}-\mathrm{Y}, \mathrm{H}-\mathrm{USY}$ zeolites were purchased from Nankai University Catalyst Co., Ltd. (Tianjin, China). All other reagents were supplied by Tianjin Kermel Chemical Reagent Co., Ltd. (Tianjin, China). The expired food in this study contained expired probiotics beverage powder, garlic powder, onion powder, burdock tea, steamed buns, and egg yolk battercake. These fructan-rich and starchy expired foods were obtained from local residents in Xi'an (Shaanxi, China).

Probiotic beverage powder is a fructan-rich health food. In addition to acidophilus, bifidobacteria, Bifidobacterium longum, Streptococcus thermophilus, and other beneficial bacteria, water soluble dietary fiber and oligofructose were added to the beverage powder to provide nutrition for the probiotics. Burdock tea is a natural tea product made from burdock (Arctium lappa L.) root. It is made by washing fresh burdock root with water followed by slicing and drying the burdock root. A $100 \mathrm{~g}$ sample of fresh burdock root contains $90.1 \mathrm{~g}$ of water, $4.1 \mathrm{~g}$ of protein, $0.1 \mathrm{~g}$ of fat, $5 \mathrm{~g}$ of carbohydrate and crude fiber, $0.7 \mathrm{~g}$ of ash, $0.03 \mathrm{mg}$ of thiamine, $0.5 \mathrm{mg}$ of ribochrome, $2 \mathrm{mg}$ of calcium, $2 \mathrm{mg}$ of iron, and $116 \mathrm{mg}$ of phosphorus. The determination methods for the contents of fructan (or starch) in these tested expired foods are shown in supporting information in the Appendix. On this basis, the contents of fructan (or starch) in expired probiotics beverage powder, onion powder, garlic powder, burdock tea, steamed buns and egg yolk battercake were $79.6 \%, 76.2 \%, 73.7 \%, 34 \%, 67.9 \%$, and $37.7 \%$ (based on dry weight), respectively. 


\section{Experimental Procedure for the Production of 5-EMF from Diverse Feedstocks}

In each batch run, catalyst $(0.02$ to $10 \mathrm{mmol})$, anhydrous ethanol (2 to $80 \mathrm{~mL}$ ), expired food feedstock (20 to $1600 \mathrm{mg}$ ), and co-solvent ( 0 to $1 \mathrm{~mL}$ ) were added and then mixed in a pressure vessel (no need for inert atmosphere). The pressure vessel was sealed through screw threads on the bottle cap. The pressure vessel was then immersed in a preheated and thermally controlled oil bath with magnetic stirring. Each pressure vessel was used for one residence time. The pressure vessel was not opened until the allocated time had elapsed. The reaction conditions were chosen based on our preliminary experiments. After the allocated time had elapsed, the vessel was removed from the oil bath and cooled in an ice bath. The sample was then immediately analyzed after dilution and filtration.

HMF and EMF were quantified by HPLC (Shimadzu LC-2010AHT, ultraviolet detector, XDB-C18 column, column oven temperature of $30{ }^{\circ} \mathrm{C}$ ). Acetonitrile $/ 0.1 \mathrm{wt} \%$ acetic acid aqueous solution with a volume ratio of 15:85 at a flow rate of $1.0 \mathrm{~mL} \mathrm{~min}{ }^{-1}$ was used as the mobile phase. The yields of EL was determined by gas chromatography (GC-PE680) equipped with flame ionization detector (FID), and a HP-5MS capillary column. The inlet temperature of the $\mathrm{GC}$ was set at $270{ }^{\circ} \mathrm{C}$, and the detector temperature was kept at $280{ }^{\circ} \mathrm{C}$. The column temperature was maintained at $120{ }^{\circ} \mathrm{C}$ for $3.3 \mathrm{~min}$, and then increased to $200{ }^{\circ} \mathrm{C}$ at a ramp rate of $80^{\circ} \mathrm{C} / \mathrm{min}$.

\section{RESULTS AND DISCUSSION}

\section{5-EMF Production from Starchy Expired Food in Pure Ethanol}

The conversion of expired starchy food into 5-EMF consisted of the following steps (Flannelly et al. 2015; Ma et al. 2017; Sun et al. 2018): hydrolysis of starch to glucose, glucose isomerization to fructose (or the reaction of glucose with ethanol to furnish ethyl glucoside), fructose dehydration to 5-HMF (or ethyl glucoside isomerization to ethyl fructoside), and etherification of 5-HMF into 5-EMF (or dehydration of ethyl fructoside to 5-EMF), as shown in Figs. 1 and 2. A time-course study on the ethanolysis of egg yolk battercake was conducted using $\mathrm{CrCl}_{3} \cdot 6 \mathrm{H}_{2} \mathrm{O}$ and $\mathrm{SnCl}_{4} \cdot 5 \mathrm{H}_{2} \mathrm{O}$ as catalysts to examine the activity to furnish 5-EMF. The catalysts of $\mathrm{CrCl}_{3} \cdot 6 \mathrm{H}_{2} \mathrm{O}$ and $\mathrm{SnCl}_{4} \cdot 5 \mathrm{H}_{2} \mathrm{O}$ were selected because they contain Lewis acid sites, and the important and decisive isomerization step for 5-EMF formation is predominantly catalyzed by a Lewis acid. Figure 3 shows that up to $22.3 \%$ of 5 -EMF was generated in the presence of $\mathrm{CrCl}_{3} \cdot 6 \mathrm{H}_{2} \mathrm{O}$, after $30 \mathrm{~min}$ at $130{ }^{\circ} \mathrm{C}$. Formation of ethyl levulinate (EL) was observed when both $\mathrm{CrCl}_{3} \cdot 6 \mathrm{H}_{2} \mathrm{O}$ and $\mathrm{SnCl}_{4} \cdot 5 \mathrm{H}_{2} \mathrm{O}$ were employed. The EL yields obtained at $130{ }^{\circ} \mathrm{C}$ were slightly higher than those obtained at $110{ }^{\circ} \mathrm{C}$, which was likely because the high temperature facilitated 5-EMF rehydration to EL. Trifluoromethyl sulfonic acid and p-toluenesulfonic acid achieved 5-EMF yields (12 mol\% to $26 \mathrm{~mol} \%$ ) comparable to those achieved with metal chlorides when starchy expired food was used as the substrate (Table 1). This may have occurred because trifluoromethyl sulfonic acid and p-toluenesulfonic acid possess strong Bronsted acid sites, and Bronsted acids are more active than Lewis acids in other reaction steps of 5-EMF synthesis, excluding isomerization (Dai et al. 2018). In addition, the yield of EL was consistently below $3 \%$, which indicated that the EL formation reaction was not remarkable under the typical reaction conditions. 


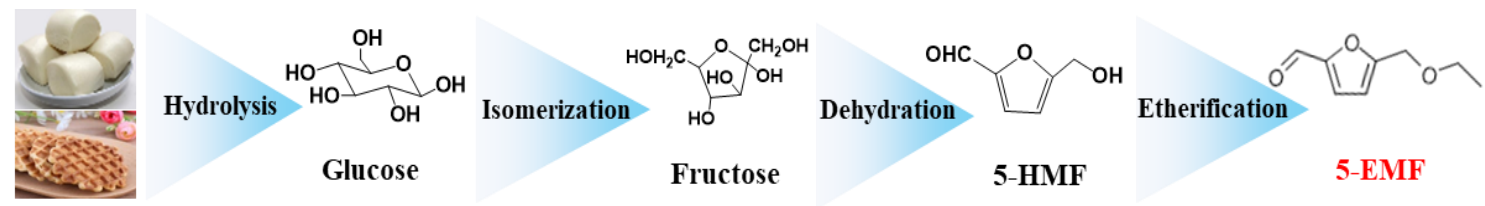

Expired starchy food

Fig. 1. The reaction pathway for 5-EMF formation from expired starchy food with 5-HMF as the intermediate

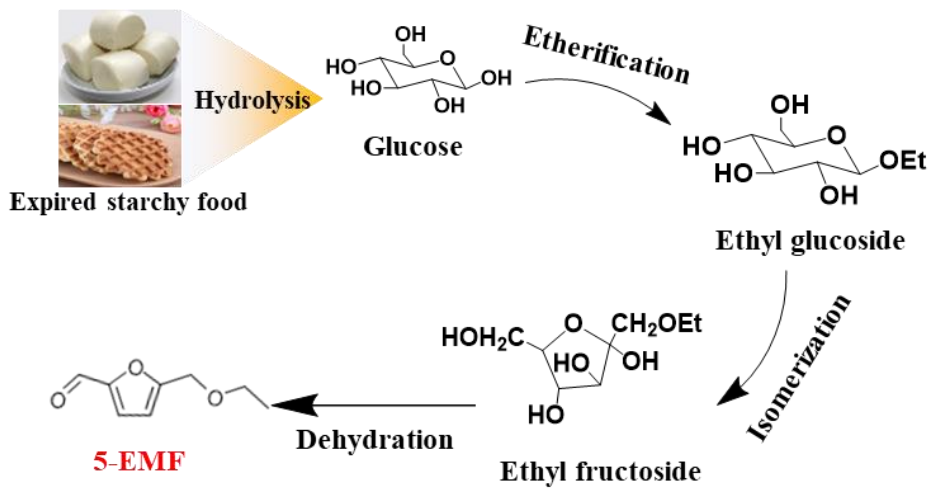

Fig. 2. The reaction pathway for 5-EMF formation from expired starchy food without 5-HMF as the intermediate
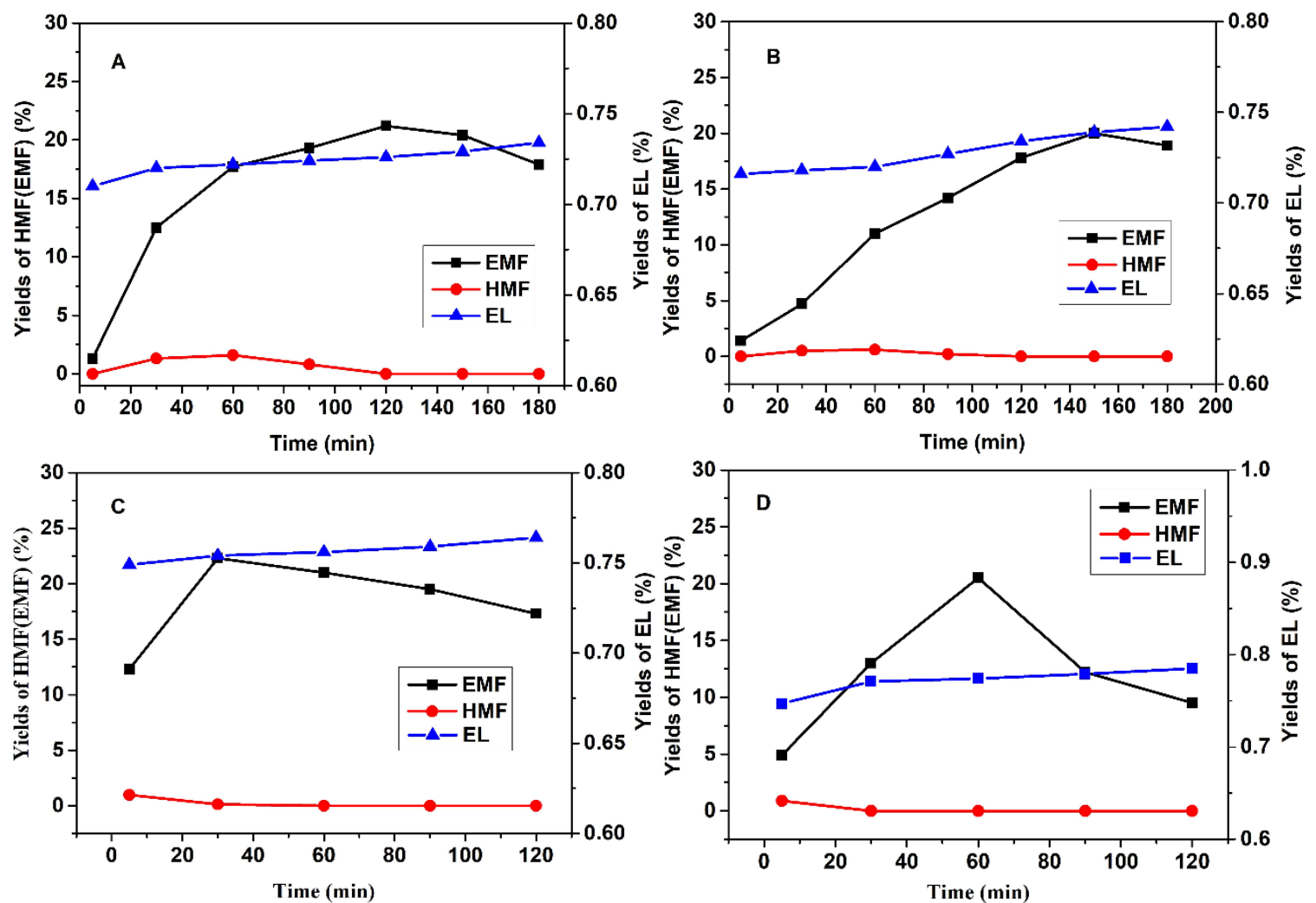

Fig. 3. The catalytic performances of metal chlorides in the conversion of expired egg yolk battercake into 5-EMF. Reaction conditions: $2 \mathrm{~mL}$ of ethanol, $20 \mathrm{mg}$ of expired egg yolk battercake, (A) $0.02 \mathrm{mmol} \mathrm{CrCl} 3 \cdot 6 \mathrm{H}_{2} \mathrm{O}, 110{ }^{\circ} \mathrm{C}$; (B) $0.02 \mathrm{mmol} \mathrm{SnCl}_{4} \cdot 5 \mathrm{H}_{2} \mathrm{O}, 110{ }^{\circ} \mathrm{C}$; (C) 0.02 $\mathrm{mmol} \mathrm{CrCl}_{3} \cdot 6 \mathrm{H}_{2} \mathrm{O}, 130{ }^{\circ} \mathrm{C}$; (D) $0.02 \mathrm{mmol} \mathrm{SnCl}_{4} \cdot 5 \mathrm{H}_{2} \mathrm{O}, 130{ }^{\circ} \mathrm{C}$ 
Table 1. Starchy Expired Food Conversion to 5-EMF in Pure Ethanol Catalyzed by Homogeneous Acids ${ }^{a}$

\begin{tabular}{|c|c|c|c|c|}
\hline Entry & Substrate & $\begin{array}{c}\text { 5-HMF Yields } \\
(\%)\end{array}$ & $\begin{array}{c}\text { 5-EMF Yields } \\
(\%)\end{array}$ & EL Yields (\%) \\
\hline 1 & Expired egg yolk battercake & I & 21.7 & 2.2 \\
\hline $2^{b}$ & Expired egg yolk battercake & 1 & 23.4 & 2.6 \\
\hline $3^{c}$ & Expired egg yolk battercake & I & 12.6 & 1.4 \\
\hline $4^{b}$ & Expired steamed bun & 0.81 & 26.8 & 2.8 \\
\hline $5^{c}$ & Expired steamed bun & 1 & 12.9 & 1.4 \\
\hline $6^{d}$ & Expired steamed bun & 1 & 11.2 & 1.1 \\
\hline \multicolumn{5}{|c|}{$\begin{array}{l}{ }^{a} \text { Reaction conditions: } 2 \mathrm{~mL} \text { of ethanol, } 20 \mathrm{mg} \text { of expired food, and } 100 \mu \mathrm{L} \text { of p-toluenesulfonic } \\
\text { acid at } 110^{\circ} \mathrm{C} \text { for } 10 \mathrm{~min} ; \mathrm{b} 100 \mu \mathrm{L} \text { of } \mathrm{p} \text {-toluenesulfonic acid at } 130^{\circ} \mathrm{C} \text { for } 10 \mathrm{~min} ;{ }^{\mathrm{c}} 5 \mu \mathrm{L} \text { of } \\
\text { trifluoromethyl sulfonic acid at } 120^{\circ} \mathrm{C} \text { for } 30 \text { min; }{ }^{\mathrm{d}} 1.6 \mathrm{~g} \text { expired steamed bun, } 80 \mathrm{~mL} \text { ethanol, } \\
10 \mathrm{mmol} \mathrm{H}_{2} \mathrm{SO}_{4} \text { at } 130^{\circ} \mathrm{C} \text { for } 30 \mathrm{~min}\end{array}$} \\
\hline
\end{tabular}

Although the starch contents of the expired steamed buns and expired egg yolk battercake differed substantially $(67.9 \%$ and $37.7 \%$, respectively), there was little difference in the 5-EMF yields on a molar basis. The copresence of more "non-starch" content in the expired egg yolk battercake did not have a notable negative influence on the overall reactivity. Further, 5-EMF production from expired steamed buns and expired egg yolk battercake only occurs in moderate yields because there are considerable challenges with obtaining 5-EMF from aldose-based polysaccharides (Alipour et al. 2017). The reaction route is long, and many by-products and intermediates are present in the reaction system. For example, the desired etherification of glucose units in starchy expired food is suppressed by several side reactions, such as acetalization and polymerization. These result in the production of recalcitrant humic substances and limit the yield of 5-EMF (Hu et al. 2011; Démolis et al. 2014; Filiciotto et al. 2018).

\section{Fructan-rich Expired Food Conversion into 5-EMF in the Presence of $\mathrm{CrCl}_{3} \cdot 6 \mathrm{H}_{2} \mathrm{O}$ or Trifluoromethyl Sulfonic Acid in Pure Ethanol}

Given the difficulty with the production of 5-EMF from glucose units, fructan-rich expired food was used to avoid the isomerization step in the ethanolysis reactions and was investigated as the feedstock for 5-EMF production. Table 2 shows that considerable yields of 5-EMF were achieved in ethanol from three kinds of fructan-rich expired foods, which included probiotic beverage powder, onion powder, and garlic powder catalyzed by $\mathrm{CrCl}_{3} \cdot 6 \mathrm{H}_{2} \mathrm{O}$ (Table 2, entries 1 to 3 ). Expired probiotic beverage powder achieved yields of 7.2\%, 31.5\%, and 7.0\% of 5-HMF, 5-EMF, and EL, respectively, after 50 min at 130 ${ }^{\circ} \mathrm{C}$. When the reaction time was extended to $70 \mathrm{~min}$, the intermediate product (5-HMF) was converted to downstream products, and the yield of 5-HMF decreased, whereas both the yield of 5-EMF and that of EL increased (Table 2, entry 4). For comparison, expired onion powder and expired garlic powder were treated under the same reaction conditions, and a similar decreasing trend for the 5-HMF yield was observed as the reaction times increased. However, contrary to the 5-EMF yield trend when expired probiotics beverage powder was used as a feedstock, the yield for 5-EMF decreased as the reaction times increased from $50 \mathrm{~min}$ to $70 \mathrm{~min}$ when expired onion powder and garlic powder were used as substrates (Table 2, entries 5 and 6). Although the contents of fructosyl moieties in the expired probiotic beverage powder, onion powder, and garlic powder were similar, expired garlic powder achieved lower 5-EF yield for all of the catalytic systems. Generally, the 5- 
EMF yields obtained from expired onion powder and garlic powder were lower than those obtained from expired probiotic beverage powder, which likely occurred because the impurities present in expired onion powder and garlic powder had adverse effects on the reaction process. Further, the varying degrees to which fructosyl moiety was polymerized in the starting materials may have influenced the product yield.

Table 2. 5-EMF Production from Expired Probiotic Beverage Powder, Onion Powder, and Garlic Powder

\begin{tabular}{|c|c|c|c|c|}
\hline Entry & Substrate & 5-HMF Yields (\%) & 5-EMF Yields (\%) & EL Yields (\%) \\
\hline $1^{a}$ & EPBP & 7.2 & 31.5 & 7.0 \\
\hline $2^{a}$ & EOP & 10.2 & 26.1 & 4.6 \\
\hline $3^{a}$ & EGP & 3.4 & 23.9 & 4.3 \\
\hline $4^{b}$ & EPBP & 4.4 & 33.0 & 7.8 \\
\hline $5^{\mathrm{b}}$ & EOP & 7.6 & 25.2 & 4.9 \\
\hline $6^{\mathrm{b}}$ & EGP & 1.9 & 22.5 & 5.3 \\
\hline $7^{c}$ & EPBP & 1 & 35.1 & 30.5 \\
\hline $8^{c}$ & EOP & 1 & 35.4 & 30.4 \\
\hline $9^{c}$ & EGP & 1 & 18.2 & 15.9 \\
\hline \multicolumn{5}{|c|}{$\begin{array}{l}\text { Reaction conditions: a } 20 \mathrm{mg} \text { of substrate, } 0.02 \mathrm{mmol} \text { of } \mathrm{CrCl}_{3} \cdot 6 \mathrm{H}_{2} \mathrm{O} \text {, and } 2 \mathrm{~mL} \text { of ethanol at } 130 \\
{ }^{\circ} \mathrm{C} \text { for } 50 \mathrm{~min} \text {; }{ }^{b} 20 \mathrm{mg} \text { of substrate, } 0.02 \mathrm{mmol} \text { of } \mathrm{CrCl}_{3} \cdot 6 \mathrm{H}_{2} \mathrm{O} \text {, and } 2 \mathrm{~mL} \text { of ethanol at } 130{ }^{\circ} \mathrm{C} \text { for } \\
70 \mathrm{~min} \text {; }{ }^{\mathrm{c}} 20 \mathrm{mg} \text { of substrate, } 2 \mathrm{~mL} \text { of ethanol, } 5 \mathrm{\mu L} \text { of trifluoromethyl sulfonic acid for } 15 \mathrm{~min} \text { at } \\
130{ }^{\circ} \mathrm{C} \text {; EPBP: Expired probiotics beverage powder; EOP: Expired onion powder; EGP: Expired } \\
\text { garlic powder. }\end{array}$} \\
\hline
\end{tabular}

The ethanolysis of fructan-rich expired food follows a multistep approach of fructan-fructose-5-HMF-5-EMF (or fructan-fructose-ethyl fructoside-5-EMF); the process involves sequential hydrolysis-dehydration-etherification (or hydrolysisetherification-dehydration) reaction steps (Unlu and Hilmioglu 2016; García-Bosch et al. 2018). Moderate total yields of "5-HMF+5-EMF+EL" (29.7 mol\% to $45.7 \mathrm{~mol} \%)$ were observed from the three raw materials in the presence of $\mathrm{CrCl}_{3} \cdot 6 \mathrm{H}_{2} \mathrm{O}$. This was because $\mathrm{CrCl}_{3} \cdot 6 \mathrm{H}_{2} \mathrm{O}$ is a Lewis acid and is not active enough to catalyze efficient hydrolysis, dehydration, and etherification. Therefore, trifluoromethyl sulfonic acid was selected for the following experiments. After heating for $15 \mathrm{~min}$ at $130{ }^{\circ} \mathrm{C}$ (Table 2 entries 7 to 9), no 5 -HMF was detected, but the amounts of EL increased for all of the tested substrates. The total "5-EMF+EL" yields reached $65.8 \mathrm{~mol} \%$, which was accomplished with expired onion powder when the reaction was conducted in ethanol at $130{ }^{\circ} \mathrm{C}$ for $15 \mathrm{~min}$. The 5-HMF, 5EMF, and EL yields with different feedstocks in Table 2 show that the reaction rate catalyzed by trifluoromethyl sulfonic acid was faster than that catalyzed by $\mathrm{CrCl}_{3} \cdot 6 \mathrm{H}_{2} \mathrm{O}$ because no 5-HMF was detected. However, a noticeable amount of the end product (EL) was obtained within $15 \mathrm{~min}$. The fast reaction rate in the presence of trifluoromethyl sulfonic acid may have been due to the strong acidic site and the homogeneous property, which are favorable for fructan depolymerization, fructose/ethyl fructoside dehydration, and 5-HMF etherification to 5-EMF in the ethanol solvent. The accumulation of EL mainly comes from the rehydration of 5-EMF and the esterification of LA (levulinic acid produced 
by the rehydration of 5-HMF) with ethanol in the acidic reaction environment (Rao et al. 2017; Liu et al. 2018; Zhou et al. 2018).

\section{Production of 5-EMF from Expired Burdock Tea Catalyzed by Various Catalysts in Pure Ethanol}

The expired garlic powder, onion powder, and probiotic beverage powder all contained more than $70 \mathrm{wt} \%$ fructosyl moieties. For comparison, expired burdock tea with $34 \mathrm{wt} \%$ fructan was selected as a feedstock for the experiments. Figure 4 shows the conversion of expired burdock tea in ethanol at $130{ }^{\circ} \mathrm{C}$. The activity of the catalysts, trifluoromethyl sulfonic acid, benzenesulfonic, acid and p-toluenesulfonic acid, were compared. Initially, 5-HMF was observed along with 5-EMF. However, as time progressed, 5-HMF decreased below the detection limit for each of the three tested organic acids. In the presence of benzenesulfonic acid, the 5-EMF yield reached a maximum of $32.3 \%$ after $40 \mathrm{~min}$, whereas a 30.2\% 5-EMF yield was achieved in the presence of trifluoromethyl sulfonic acid after $20 \mathrm{~min}$. In addition, p-toluenesulfonic acid had higher catalytic activity than both benzenesulfonic acid and trifluoromethyl sulfonic acid, as a 5EMF yield of $40.7 \%$ was observed.
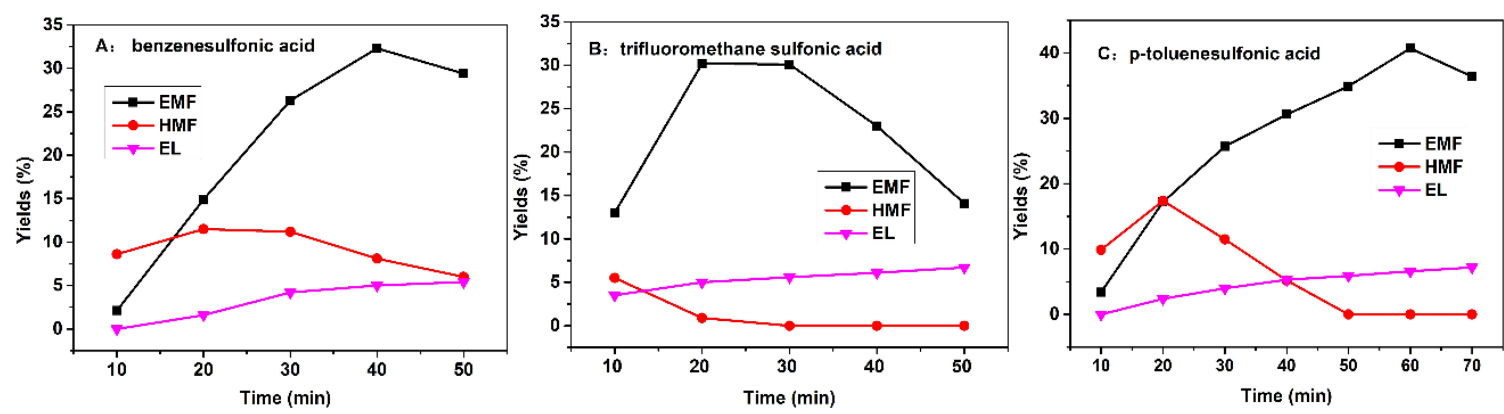

Fig. 4. Effect of reaction time on expired burdock tea conversion into 5-EMF catalyzed by organic acids; reaction conditions: $60 \mathrm{mg}$ of expired burdock tea and $0.1 \mathrm{mmol}$ of catalyst at $110^{\circ} \mathrm{C}$

Further, a series of experiments were carried out to evaluate the catalytic activity of several mineral acids, heteropolyacids, and solid acids for the conversion of expired burdock tea into 5-EMF, and the results are shown in Table 3. The obtained 5-EMF yields were between $0.2 \%$ and $40.4 \%$ with these catalysts. The formation of EL was also observed with all catalysts, and the values ranged from $0.2 \%$ to $9.6 \%$. The $\mathrm{H}_{2} \mathrm{SO}_{4}$ gave a comparable yield of 5-EMF to that of p-toluenesulfonic acid (Fig. 4C). Among the tested chlorides, the 5 -EMF yields are arranged in descending order from entry 2 to entry 5 (Table 3). The $\mathrm{AlCl}_{3}$ exhibited the best performance with a 32.9\% 5-EMF yield achieved. Among the solid acids employed, Amberlyst-15 was the most efficient catalyst for the conversion of expired burdock tea to 5-EMF, as it yielded $14.4 \%$ 5-EMF and $0.9 \%$ EL. It was noteworthy that a small amount of furfural was also detected in these reactions. The produced furfural mainly originated from the $\mathrm{C}_{5}$ carbohydrates in the expired burdock tea.

The content of fructosyl moieties in expired burdock tea and that in fructan-rich substrates (expired probiotic beverage powder, onion powder, garlic powder) differed substantially (34\% and $73.7-79.6 \%$, respectively), and there were large differences in the total "5-HMF+5-EMF+EL" yields regardless of the reaction conditions, which indicated that increases in the non-fructan proportion of expired burdock tea had a notable negative influence on the reaction process. 
Table 3. Ethanolysis of Expired Burdock Tea in the Presence of Various Catalysts $^{\text {a }}$

\begin{tabular}{|c|c|c|c|c|c|c|c|}
\hline Entry & Catalyst & $\begin{array}{c}T \\
\left({ }^{\circ} \mathrm{C}\right)\end{array}$ & $\begin{array}{c}t \\
(\min )\end{array}$ & $\begin{array}{l}\text { Catalyst } \\
\text { Dosage }\end{array}$ & $\begin{array}{l}\text { 5-HMF Yield } \\
\text { (mol\%) }\end{array}$ & $\begin{array}{l}\text { 5-EMF } \\
\text { Yield } \\
\text { (mol\%) }\end{array}$ & $\begin{array}{c}\text { EL Yield } \\
\text { (mol\%) }\end{array}$ \\
\hline 1 & $\mathrm{H}_{2} \mathrm{SO}_{4}$ & 130 & 15 & $0.1 \mathrm{mmol}$ & 5 & 40.4 & 5.4 \\
\hline 2 & $\mathrm{AlCl}_{3}$ & 130 & 30 & $0.2 \mathrm{mmol}$ & 0 & 32.9 & 4.3 \\
\hline 3 & $\mathrm{SnCl}_{4}$ & 130 & 30 & $0.2 \mathrm{mmol}$ & 3.1 & 15.4 & 2.6 \\
\hline 4 & $\mathrm{FeCl}_{3}$ & 130 & 30 & $0.2 \mathrm{mmol}$ & 1 & 5.9 & 0.5 \\
\hline 5 & $\mathrm{CrCl}_{3} \cdot 6 \mathrm{H}_{2} \mathrm{O}$ & 130 & 30 & $0.2 \mathrm{mmol}$ & 1 & 1.5 & 0.4 \\
\hline 6 & $\mathrm{H}_{3} \mathrm{PW}_{12} \mathrm{O}_{40}$ & 138 & 130 & $34.5 \mathrm{mg}$ & 2.2 & 19.1 & 2.8 \\
\hline 7 & $\mathrm{H}_{3} \mathrm{PMo}_{12} \mathrm{O}_{40}$ & 138 & 130 & $22.1 \mathrm{mg}$ & 6 & 12.2 & 2.7 \\
\hline 8 & $\mathrm{H}_{4} \mathrm{SiW}_{12} \mathrm{O}_{40}$ & 138 & 130 & $34.5 \mathrm{mg}$ & 0.8 & 17.9 & 2.8 \\
\hline 9 & Sulfamic acid & 138 & 130 & $0.1 \mathrm{mmol}$ & 8.2 & 0.2 & 2.7 \\
\hline 10 & $\begin{array}{l}\text { p-aminobenzene } \\
\text { sulfonic acid }\end{array}$ & 138 & 130 & $0.05 \mathrm{mmol}$ & 22.7 & 1.3 & 2.7 \\
\hline $11^{\mathrm{b}}$ & $\mathrm{H}$-beta & 150 & $12 \mathrm{~h}$ & $40 \mathrm{mg}$ & 2.7 & 1.8 & 1.5 \\
\hline $12^{\mathrm{b}}$ & $\mathrm{H}-\mathrm{Y}$ & 150 & $12 \mathrm{~h}$ & $40 \mathrm{mg}$ & 0 & 6.7 & 2.7 \\
\hline $13^{b}$ & H-USY & 150 & $12 \mathrm{~h}$ & $40 \mathrm{mg}$ & 0 & 7.4 & 3.2 \\
\hline $14^{\mathrm{b}}$ & Amberlyst-15 & 150 & $12 \mathrm{~h}$ & $40 \mathrm{mg}$ & 1 & 14.4 & 0.9 \\
\hline $15^{c}$ & $\begin{array}{l}\text { Trifluoromethyl } \\
\text { sulfonic acid }\end{array}$ & 130 & 15 & $5 \mu \mathrm{L}$ & 1 & 11 & 9.6 \\
\hline $16^{c}$ & $\mathrm{CrCl}_{3} \cdot 6 \mathrm{H}_{2} \mathrm{O}$ & 130 & 70 & $0.02 \mathrm{mmol}$ & 0 & 1.2 & 0.2 \\
\hline
\end{tabular}

\section{Table 4. Effect of Co-solvent on 5-EMF Production from Fructan-rich Expired} Food

\begin{tabular}{|c|c|c|c|c|c|c|c|}
\hline Entry & Substrate & Catalyst & Solvent & Co-solvent & $\begin{array}{c}\text { 5-HMF } \\
\text { Yield (\%) }\end{array}$ & $\begin{array}{c}\text { 5-EMF } \\
\text { Yield (\%) }\end{array}$ & $\begin{array}{c}\text { EL Yield } \\
(\%)\end{array}$ \\
\hline $1^{a}$ & EPBP & $\mathrm{CrCl}_{3} \cdot 6 \mathrm{H}_{2} \mathrm{O}$ & $1.9 \mathrm{~mL}$ ethanol & $0.1 \mathrm{~mL} \mathrm{H}{ }_{2} \mathrm{O}$ & 25.2 & 8.6 & 2.2 \\
\hline $2^{a}$ & EPBP & $\mathrm{CrCl}_{3} \cdot 6 \mathrm{H}_{2} \mathrm{O}$ & $1.9 \mathrm{~mL}$ ethanol & $0.1 \mathrm{~mL}$ DMSO & 43.4 & 12.4 & 4.1 \\
\hline $3^{a}$ & EPBP & $\mathrm{CrCl}_{3} \cdot 6 \mathrm{H}_{2} \mathrm{O}$ & $1.9 \mathrm{~mL}$ ethanol & $0.1 \mathrm{~mL}$ THF & 16.2 & 30.3 & 4.2 \\
\hline $4^{b}$ & EPBP & TSA & $1.8 \mathrm{~mL}$ ethanol & $0.2 \mathrm{~mL}$ DMSO & 8.7 & 68.3 & 19.3 \\
\hline $5^{b}$ & EOP & TSA & $1.8 \mathrm{~mL}$ ethanol & $0.2 \mathrm{~mL}$ DMSO & 10.1 & 64.9 & 17.2 \\
\hline $6^{b}$ & EGP & TSA & $1.8 \mathrm{~mL}$ ethanol & $0.2 \mathrm{~mL}$ DMSO & 2.4 & 31.3 & 11.7 \\
\hline $7^{c}$ & EPBP & TSA & $1.8 \mathrm{~mL}$ ethanol & $0.2 \mathrm{~mL}$ DMSO & ND & 57.7 & 31.7 \\
\hline $8^{c}$ & EOP & TSA & $1.8 \mathrm{~mL}$ ethanol & $0.2 \mathrm{~mL}$ DMSO & 0.8 & 64.0 & 21.9 \\
\hline $9^{c}$ & EGP & TSA & $1.8 \mathrm{~mL}$ ethanol & $0.2 \mathrm{~mL}$ DMSO & ND & 30.1 & 17.9 \\
\hline $10^{d}$ & EBT & $\mathrm{H}-\mathrm{Y}$ & $2 \mathrm{~mL}$ ethanol & $1 \mathrm{~mL}$ DMSO & 17.8 & 4.4 & 2.4 \\
\hline $11^{d}$ & EBT & H-USY & $2 \mathrm{~mL}$ ethanol & $1 \mathrm{~mL}$ DMSO & 47.4 & 1 & 1.3 \\
\hline $12^{d}$ & EBT & Amberlyst-15 & $2 \mathrm{~mL}$ ethanol & $1 \mathrm{~mL}$ DMSO & 19.3 & 28.1 & 8.8 \\
\hline \multicolumn{8}{|c|}{$\begin{array}{l}\text { a Reaction conditions: } 20 \mathrm{mg} \text { of substrate, } 0.02 \mathrm{mmol} \mathrm{CrCl}_{3} \cdot 6 \mathrm{H}_{2} \mathrm{O} \text { at } 130^{\circ} \mathrm{C} \text { for } 70 \mathrm{~min} ;{ }^{\mathrm{b}} 0.05 \mathrm{mmol} \\
\text { trifluoromethyl sulfonic acid at } 130^{\circ} \mathrm{C} \text { for } 15 \mathrm{~min} ;{ }^{\mathrm{c}} 0.05 \mathrm{mmol} \text { trifluoromethyl sulfonic acid at } 130^{\circ} \mathrm{C} \text { for } 20 \\
\text { min; }{ }^{d} \text { the other conditions were the same as entries } 12,13 \text {, and } 16 \text { in Table 3; EPBP: Expired probiotics } \\
\text { beverage powder; EOP: Expired onion powder; EGP: Expired garlic powder; EBT: Expired burdock tea; } \\
\text { TSA: trifluoromethyl sulfonic acid }\end{array}$} \\
\hline
\end{tabular}




\section{Effect of Co-solvent on 5-EMF Yields}

In addition to the effects of temperature and time, a co-solvent may also affect the conversion of expired food to 5-EMF because adding specific solvents can change the characteristics of the reaction solvent, which could lead to unique solvent effects (Yuriy et al. 2006). Thus, DMSO, THF, and water were selected as co-solvents, and the results are summarized in Table 4.

Compared with the results in Table 2, entry 1, when $\mathrm{CrCl}_{3} \cdot 6 \mathrm{H}_{2} \mathrm{O}$ was used as the catalyst for expired probiotic beverage powder conversion, the introduction of DMSO caused side effects, and the yield of 5-EMF decreased remarkably (Table 4, entry 2). Although THF has been reported to improve 5-EMF yields when Amberlyst-15 or $\mathrm{H}_{3} \mathrm{PW}_{12} \mathrm{O}_{40}$ are used as catalysts (Zhu et al. 2011; Yang et al. 2012), the introduction of a small amount of THF reduced the yield of 5-EMF (Table 4, entry 3). Further, the addition of small amounts of $\mathrm{H}_{2} \mathrm{O}$ also caused a noticeable decrease in the yield of 5-EMF (Table 4, entry 1), and similar results were reported previously (Di et al. 2018).

However, compared with the results in Table 2, entries 7 to 9, when trifluoromethyl sulfonic acid was employed as the catalyst, the introduction of $10 \mathrm{vol} \%$ DMSO greatly improved the 5-EMF yield and decreased the EL yield over the 15 min reaction time. The yield of 5-EMF increased sharply from $35.1 \%$ to $68.3 \%$, and the yield of EL decreased from $30.5 \%$ to $19.3 \%$ when the expired probiotic beverage powder was tested (Table 4, entry 4). Expired onion powder and garlic powder showed a similar trend for product yields when DMSO was added as the co-solvent in the presence of trifluoromethyl sulfonic acid. When the expired onion powder was used as the raw material, the 5-EMF yield increased from $35.4 \%$ to $64.9 \%$, and the EL yield decreased from $30.4 \%$ to $17.2 \%$ (Table 4 , entry 5). Using expired garlic powder resulted in a 5-EMF yield increase from $18.2 \%$ to $31.3 \%$, and the EL yield decreased from $15.9 \%$ to $11.7 \%$ (Table 4, entry 6). Prolonging the reaction time to 20 min decreased the yield of 5-EMF for all three substrates, but the yield of EL increased notably (entries 7 to 9 in Table 4). Controlling the formation of 5-EMF was challenging, as it is rapidly rehydrated to form EL in the presence of strong acid catalysts.

To explore the effect of adding a second organic solvent on the production of 5EMF in the presence of solid acids, the introduction of DMSO to the reaction systems for expired burdock tea ethanolysis was investigated. As demonstrated in Table 4 (entries 10 to 12), for H-Y and H-USY, the addition of DMSO lowered the yield of 5-EMF, but greatly increased the 5-HMF yields. However, both the yield of 5-EMF and that of 5-HMF increased when Ambelyst-15 was used as a catalyst.

The results above indicated that the effect of a co-solvent depended largely on the catalyst type, whereas it was not closely related to the properties of the feedstock.

\section{CONCLUSIONS}

1. Several fructan-rich and starchy expired food (expired probiotic beverage powder, onion powder, garlic powder, burdock tea, steamed buns, and egg yolk battercake) were tested as raw substrates for 5-EMF production. The catalytic performances of different homogeneous and heterogeneous catalysts were evaluated. The conversion of expired food to 5-EMF depended on factors of substrate properties, catalyst type and loading, reaction time, temperature, and the presence of a co-solvent. 
2. Expired steamed buns resulted in a 26.8\% 5-EMF yield when p-toluenesulfonic acid was used as a catalyst. Fructan-rich expired food was better than starchy expired food for 5-EMF production, and peak yields of 68\% 5-EMF were achieved from expired probiotic beverage powder. For the four tested fructan-rich expired food, increased "non-fructan" content negatively influenced the 5-EMF yield. However, for the two tested starchy expired foods, although the starch contents were remarkably different, the 5-EMF molar yields from expired egg yolk battercake were close to that obtained from expired steamed buns, which indicated that the increased amounts of "non-starch" components in the expired egg yolk battercake did not negatively affect the overall reaction noticeably.

3. Compared to the ketose-based fructan-rich expired food, aldose based starchy expired food was more difficult to convert into 5-EMF. The effect of co-solvents on 5-EMF yield was not strongly related to substrate properties but was related to catalyst type.

\section{ACKNOWLEDGEMENTS}

The authors gratefully acknowledge the National Natural Science Foundation of China (Grant No. 21607119), the Key Research and Development Plan of Shaanxi Province-Industrial Innovation Chain Project (Grant No. 2020ZDLNY06-08), the Special Funds of the Education Department of Shaanxi Province (Grant No. 19JK0475), the Young Talents Support Program of Colleges and Universities Association for Science and Technology of Shaanxi Province (Grant No. 20190420), the Innovative Talents Promotion Plan-Science and Technology Innovation Group of Shaanxi Province (Grant No. 2019TD025), the Special Program in Natural Science of Xi'an University of Architecture and Technology (Grant No. ZR19020) and the 15th SSRT Program of Xi'an University of Architecture and Technology (Grant No. 1595).

\section{REFERENCES CITED}

Abeliotis, K., Lasaridi, K., Costarelli, V., and Chroni, C. (2015). "The implications of food waste generation on climate change: The case of Greece," Sustainable Production and Consumption 3, 8-14. DOI: 10.1016/j.spc.2015.06.006

Ahmad, E., Alam, M. I., Pant, K. K., and Haider, M. A. (2016). "Catalytic and mechanistic insights into the production of ethyl levulinate from biorenewable feedstocks," Green Chemistry 18, 4804-4823. DOI: 10.1039/c6gc01523a

Alipour, S., Omidvarborna, H., and Kim, D.-S. (2017). “A review on synthesis of alkoxymethyl furfural, a biofuel candidate," Renewable and Sustainable Energy Reviews 71, 908-926. DOI: 10.1016/j.rser.2016.12.118

Arancon, R. A. D., Lin, C. S. K., Chan, K. M., Kwan, T. H., and Luque, R. (2013). "Advances on waste valorization: New horizons for a more sustainable society," Energy Science \& Engineering 1(2), 53-71. DOI: 10.1002/ese3.9

Chen, S. S., Yu, I. K. M., Tsang, D. C. W., Yip, A. C. K., Khan, E., Wang, L., Ok, Y. S., and Poon, C. S. (2017). "Valorization of cellulosic food waste into levulinic acid catalyzed by heterogeneous Brønsted acids: Temperature and solvent effects," Chemical Engineering Journal 327, 328-335. DOI: 10.1016/j.cej.2017.06.108 
Chen, T., Peng, L., Yu, X., and He, L. (2018). "Magnetically recyclable cellulose-derived carbonaceous solid acid catalyzed the biofuel 5-ethoxymethylfurfural synthesis from renewable carbohydrates," Fuel 219, 344-352. DOI: 10.1016/j.fuel.2018.01.129

Dai, J., Peng, L., and Li, H. (2018). "Intensified ethyl levulinate production from cellulose using a combination of low loading $\mathrm{H}_{2} \mathrm{SO}_{4}$ and $\mathrm{Al}(\mathrm{OTf})_{3}$," Catalysis Communications 103, 116-119. DOI: 10.1016/j.catcom.2017.10.007

Démolis, A., Essayem, N., and Rataboul, F. (2014). "Synthesis and applications of alkyl levulinates," ACS Sustainable Chemistry \& Engineering 2(6), 1338-1352. DOI: $10.1021 / \mathrm{sc} 500082 \mathrm{n}$

Di Bitonto, Antonopoulou, G., Braguglia, C., Campanale, C., Gallipoli, A., Lyberatos, G., Ntaikou, I., and Pastore, C. (2018). "Lewis-Brønsted acid catalysed ethanolysis of the organic fraction of municipal solid waste for efficient production of biofuels," Bioresource Technology 266, 297-305. DOI: 10.1016/j.biortech.2018.06.110

Food and Agriculture Organization of the United Nations. (2011). Global Food Losses and Food Waste. Extent, Causes and Prevention, FAO, Rome, Italy.

Filiciotto, L., Balu, A. M., Van der Waal, J. C., and Luque, R. (2018). "Catalytic insights into the production of biomass-derived side products methyl levulinate, furfural and humins," Catalysis Today 302, 2-15. DOI: 10.1016/j.cattod.2017.03.008

Flannelly, T., Dooley, S., and Leahy, J. J. (2015). "Reaction pathway analysis of ethyl levulinate and 5-ethoxymethylfurfural from d-fructose acid hydrolysis in ethanol," Energy \& Fuels 29(11), 7554-7565. DOI: 10.1021/acs.energyfuels.5b01481

Galaverna, R., Breitkreitz, M. C., and Pastre, J. C. (2018). "Conversion of D-fructose to 5-(hydroxymethyl)furfural: Evaluating batch and continuous flow conditions by design of experiments and in-line FTIR monitoring," ACS Sustainable Chemistry \& Engineering 6(3), 4220-4230. DOI: 10.1021/acssuschemeng.7b04643

García-Bosch, N., Bachiller-Baeza, B., Rodríguez-Ramos, I., and Guerrero-Ruiz, A. (2018). "Fructose transformations in ethanol using carbon supported polyoxometalate acidic solids for 5-ethoxymethylfurfural production," ChemCatChem 10(17), 37463753. DOI: $10.1002 /$ cctc. 201800657

Gawade, A. B., and Yadav, G. D. (2018). "Microwave assisted synthesis of 5ethoxymethylfurfural in one pot from D-fructose by using deep eutectic solvent as catalyst under mild condition," Biomass and Bioenergy 117, 38-43. DOI: 10.1016/j.biombioe.2018.07.008

Guo, H., Duereh, A., Hiraga, Y., Qi, X., and Smith, R. L. (2018). "Mechanism of glucose conversion into 5-ethoxymethylfurfural in ethanol with hydrogen sulfate ionic liquid additives and a Lewis acid catalyst," Energy \& Fuels 32(8), 8411-8419. DOI: 10.1021/acs.energyfuels.8b00717

Hu, X., Lievens, C., Larcher, A., and Li, C. Z. (2011). "Reaction pathways of glucose during esterification: Effects of reaction parameters on the formation of humin type polymers," Bioresource Technology 102(21), 10104-10113. DOI: 10.1016/j.biortech.2011.08.040

Huang, Y.-B., Yang, T., Lin, Y.-T., Zhu, Y.-Z., Li, L.-C., and Pan, H. (2018). "Facile and high-yield synthesis of methyl levulinate from cellulose," Green Chemistry 20(6), 1323-1334. DOI: $10.1039 / \mathrm{c} 7 \mathrm{gc02883 \textrm {k }}$

Karmee, S. K., and Lin, C. S. K. (2014). "Valorisation of food waste to biofuel: Current trends and technological challenges," Sustainable Chemical Processes 2, Article Number 22. DOI: 10.1186/s40508-014-0022-1 
Liu, C., Feng, Q., Yang, J., and Qi, X. (2018). "Catalytic production of levulinic acid and ethyl levulinate from uniconazole-induced duckweed (Lemna minor)," Bioresource Technology 255, 50-57. DOI: 10.1016/j.biortech.2018.01.087

Ma, Y., Tan, W., Wang, K., Wang, J., Jiang, J., and Xu, J. (2017). “An insight into the selective conversion of bamboo biomass to ethyl glycosides," ACS Sustainable Chemistry \& Engineering 5(7), 5880-5886. DOI: 10.1021/acssuschemeng.7b00618

Mak, T. M. W., Xiong, X., Tsang, D. C. W., Yu, I. K. M., and Poon, C. S. (2020). "Sustainable food waste management towards circular bioeconomy: Policy review, limitations and opportunities," Bioresource Technology 297, article ID 122497. DOI: 10.1016/j.biortech.2019.122497

Parshetti, G. K., Suryadharma, M. S., Pham, T. P. T., Mahmood, R., and Balasubramanian, R. (2015). "Heterogeneous catalyst-assisted thermochemical conversion of food waste biomass into 5-hydroxymethylfurfural," Bioresource Technology 178, 19-27. DOI: 10.1016/j.biortech.2014.10.066

Pfaltzgraff, L. A., Bruyn, M. D., Cooper, E. C., Budarin, V., and Clark, J. H. (2013). "Food waste biomass: A resource for high-value chemicals," Green Chemistry 15(2), 307-314. DOI: 10.1039/c2gc36978h

Pham, T. P. T., Kaushik, R., Parshetti, G. K., Mahmood, R., and Balasubramanian, R. (2015). "Food waste-to-energy conversion technologies: Current status and future directions," Waste Management 38, 399-408. DOI: 10.1016/j.wasman.2014.12.004

Rao, B. S., Kumari, K. P., Lakshmi, D. D., and Nakka, L. (2017). "One pot selective transformation of biomass derived chemicals towards alkyl levulinates over titanium exchanged heteropoly tungstate catalysts," Catalysis Today 309, 269-275. DOI: 10.1016/j.cattod.2017.05.040

Sun, Y., Zhang, Q., Zhang, P., Song, D., and Guo, Y. (2018). "Nitrogen-doped carbonbased acidic ionic liquid hollow nanospheres for efficient and selective conversion of fructose to 5-ethoxymethylfurfural and ethyl levulinate," ACS Sustainable Chemistry \& Engineering 6(5), 6771-6782. DOI: 10.1021/acssuschemeng.8b00570

Tyagi, U., Anand, N., and Kumar, D. (2018). "Synergistic effect of modified activated carbon and ionic liquid in the conversion of microcrystalline cellulose to 5hydroxymethyl furfural," Bioresource Technology 267, 326-332. DOI: 10.1016/j.biortech.2018.07.035

Unlu, D., and Hilmioglu, N. D. (2016). "Synthesis of ethyl levulinate as a fuel bioadditive by a novel catalytically active pervaporation membrane," Energy \& Fuels 30(4), 2997-3003. DOI: 10.1021/acs.energyfuels.5b02911

Unlu, D., Ilgen, O., and Hilmioglu, N. D. (2016). "Biodiesel additive ethyl levulinate synthesis by catalytic membrane: $\mathrm{SO}_{4}{ }^{-2} / \mathrm{ZrO}_{2}$ loaded hydroxyethyl cellulose," Chemical Engineering Journal 302, 260-268. DOI: 10.1016/j.cej.2016.05.047

Wang, H., Deng, T., Wang, Y., Qi, Y., Hou, X., and Zhu, Y. (2013). "Efficient catalytic system for the conversion of fructose into 5-ethoxymethylfurfural," Bioresource Technology 136, 394-400. DOI: 10.1016/j.biortech.2013.02.110

Xiong, X., Yu, I. K. M., Tsang, D. C. W., Bolan, N. S., Sik Ok, Y., Igalavithana, A. D., Kirkham, M. B., Kim, K.-H., and Vikrant, K. (2019). "Value-added chemicals from food supply chain wastes: State-of-the-art review and future prospects," Chemical Engineering Journal 375, article ID 121983. DOI: 10.1016/j.cej.2019.121983

Xu, G., Zhang, S., Zheng, Z., Wang, C., Wang, S., and Tao, H. (2020). "Direct conversion of fructose to 5-ethoxymethylfurfural catalyzed by ultra stable Y zeolite," BioResources 15(2), 3621-3635. DOI: 10.15376/biores.15.2.3621-3635 
Yang, Y., Abu-Omar, M. M., and Hu, C. (2012). "Heteropolyacid catalyzed conversion of fructose, sucrose, and inulin to 5-ethoxymethylfurfural, a liquid biofuel candidate," Applied Energy 99, 80-84. DOI: 10.1016/j.apenergy.2012.04.049

Yu, I. K. M., Tsang, D. C. W., Yip, A. C. K., Chen, S. S., Ok, Y. S., and Poon, C. S. (2016). "Valorization of food waste into hydroxymethylfurfural: Dual role of metal ions in successive conversion steps," Bioresource Technology 219, 338-347. DOI: 10.1016/j.biortech.2016.08.002

Yu, I. K. M., Tsang, D. C. W., Yip, A. C. K., Chen, S. S., Ok, Y. S., and Poon, C. S. (2017). "Valorization of starchy, cellulosic, and sugary food waste into hydroxymethylfurfural by one-pot catalysis," Chemosphere 184, 1099-1107. DOI: 10.1016/j.chemosphere.2017.06.095

Yu, I. K. M., and Tsang, D. C. W. (2017). "Conversion of biomass to hydroxymethylfurfural: A review of catalytic systems and underlying mechanisms," Bioresource Technology 238, 716-732. DOI: 10.1016/j.biortech.2017.04.026

Yu, X., Gao, X., Peng, L., He, L., and Zhang, J. (2018). "Intensified 5-ethoxymethylfurfural production from biomass components over aluminum-based mixed-acid catalyst in co-solvent medium," ChemistrySelect 3(47), 13391-13399. DOI: 10.1002/slct.201803059

Yu, I. K. M., Ong, K. L., Tsang, D. C. W., Haque, M. A., Kwan, T. H., Chen, S. S., Uisan, K., Kulkarni, S., and Lin, C. S. K. (2018). "Chemical transformation of food and beverage waste-derived fructose to hydroxymethylfurfural as a value-added product," Catalysis Today 314, 70-77. DOI: 10.1016/j.cattod.2018.01.011

Yuriy, R. L., Chheda, J. N., and Dumesic, J. A. (2006). "Phase modifiers promote efficient production of hydroxymethylfurfural from fructose," Science 312, 1933 1937. DOI: $10.1126 /$ science. 1126337

Zhai, Y., Wang, T., Zhu, Y., Peng, C., Wang, B., Li, X., Li, C., and Zeng, G. (2018). "Production of fuel pellets via hydrothermal carbonization of food waste using molasses as a binder," Waste Management 77, 185-194. DOI:

10.1016/j.wasman.2018.05.022

Zhang, J., Dong, K., Luo, W., and Guan, H. (2018). "Catalytic upgrading of carbohydrates into 5-ethoxymethylfurfural using $\mathrm{SO}_{3} \mathrm{H}$ functionalized hyper-crosslinked polymer based carbonaceous materials," Fuel 234, 664-673. DOI: 10.1016/j.fuel.2018.07.060

Zhou, L., He, Y., Ma, L., Jiang, Y., Huang, Z., Yin, L., and Gao, J. (2018). “Conversion of levulinic acid into alkyl levulinates: Using lipase immobilized on meso-molding three-dimensional macroporous organosilica as catalyst," Bioresource Technology 247, 568-575. DOI: 10.1016/j.biortech.2017.08.134

Zhu, H., Cao, Q., Li, C., and Mu, W. (2011). "Acidic resin-catalysed conversion of fructose into furan derivatives in low boiling point solvents," Carbohydrate Research 346(13), 2016-2018. DOI: 10.1016/j.carres.2011.05.026

Zhu, S., Guo, J., Wang, X., Wang, J., and Fan, W. (2017). “Alcoholysis: A promising technology for conversion of lignocellulose and platform chemicals," ChemSusChem 10(12), 2547-2559. DOI: 10.1002/cssc.201700597

Article submitted: April 9, 2021; Peer review completed: June 7, 2021; Revised version received and accepted: July 20, 2021; Published: July 23, 2021.

DOI: 10.15376/biores.16.3.6186-6200 


\section{APPENDIX}

\section{Supplementary Information}

\section{Determination of Fructan Content and Starch Content}

Fructan content of expired probiotics beverage powder, onion powder, garlic powder, and burdock tea were measured based on the Chinese national standards for food safety: "Determination of fructan in food" (GB 5009.255-2016). The starch content in expired steamed buns and egg yolk battercake were measured based on the Chinese national standards for food safety: "Determination of starch in food" (GB 5009.9-2016).

\section{Calculation of Products Yields}

For fructan-rich expired food, product yields were calculated on a molar basis as follows:

$$
\begin{aligned}
& \text { HMF yield }(\mathrm{mol} \%)=\frac{\text { moles of HMF produced }}{\text { moles of fructosyl moiety in expired food }} \times 100 \\
& \text { EMF yield }(\mathrm{mol} \%)=\frac{\text { moles of EMF produced }}{\text { moles of fructosyl moiety in expired food }} \times 100 \\
& \text { EL yield }(\mathrm{mol} \%)=\frac{\text { moles of EL produced }}{\text { moles of fructosyl moiety in expired food }} \times 100
\end{aligned}
$$

For expired steamed buns and egg yolk battercake, all the products were calculated in a similar method as mentioned above but based on the content of glucosyl moieties.

\section{LC-MS Profile of the Products}

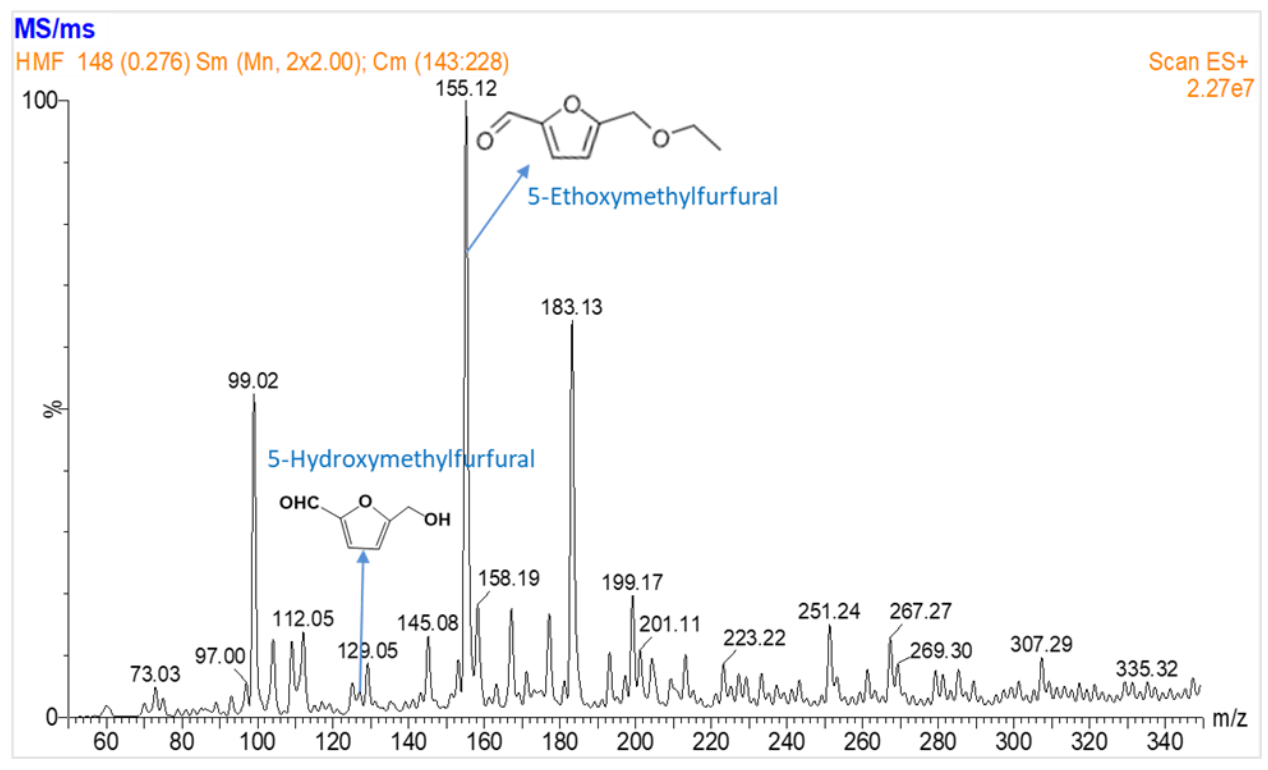

Fig. S1. LC-MS profile of the products 